\title{
Rapid 2-stage Norwood I for high-risk hypoplastic left heart syndrome and variants
}

\author{
Marcello Gomide, MD, ${ }^{a}$ Barbara Furci, MD, ${ }^{b}$ Branko Mimic, MD, ${ }^{a}$ Kate L. Brown, MD, \\ Tain-Yen Hsia, MD, ${ }^{\mathrm{a}}$ Robert Yates, MD, ${ }^{\mathrm{a}, \mathrm{b}}$ Martin Kostolny, MD, ${ }^{\mathrm{a}, \mathrm{b}}$ Marc R. de Leval, MD, ${ }^{\mathrm{a}, \mathrm{b}}$ and \\ Victor T. Tsang, MD ${ }^{a, b}$
}

\begin{abstract}
Objectives: Preoperative comorbidities (PCMs) are known risk factors for Norwood stage I (NW1). We tested the hypothesis that short-term bilateral pulmonary arterial banding (bPAB) before NW1 could improve the prognosis of these high-risk patients.
\end{abstract}

\begin{abstract}
Methods: From January 2006 to October 2011, 17 high-risk patients with hypoplastic left heart syndrome (defined as having $\geq 4$ of the following PCMs: prolonged mechanical ventilation; older age; sepsis; necrotizing enterocolitis; hepatic, renal, or heart failure; coagulopathy; pulmonary edema; high inotropic requirements; anasarca; weight $<2.5 \mathrm{~kg}$; and cardiac arrest) were identified. In addition to conventional treatment of PCMs, they underwent bPAB before NW1. BPAB was undertaken with Silastic slings and secured with ligaclips to a luminal diameter of approximately 3.5 to $4.0 \mathrm{~mm}$. The patency of the ductus arteriosus was maintained with prostaglandin. NW1 was performed using a modified, right Blalock-Taussig shunt at a median interval of 8 days after bPAB. The data from these patients were retrospectively reviewed, and the 30-day mortality and 1-year survival were compared with the hypoplastic left heart syndrome population who underwent primary NW1 with $<3$ PCMs in the same period.
\end{abstract}

Results: Of the bPAB patients, 5 (29.4\%) died before NW1. All had $\geq 5$ PCMs. Twelve patients $(70.6 \%)$ survived to undergo NW1. One early death occurred after NW1 $(8.3 \%)$. The 1-year survival rate for high-risk patients who underwent NW1 was $66.7 \%$. The early mortality and 1-year survival for the 130 patients with $<3$ PCMs was $10 \%$ and $80 \%$, respectively.

Conclusions: Optimizing the balance between the pulmonary and systemic blood flow with a short period of bPAB and ductal patency can improve the perioperative conditions of high-risk patients before NW1. Those who survived bPAB and underwent NW1 had early mortality and 1-year survival comparable to the standard risk category, despite the severity of their initial condition. A rapid 2-stage NW1 strategy with bPAB and prostaglandin to maintain ductal patency can avoid the risks of suboptimal palliation and vascular injuries associated with hybrid procedures. (J Thorac Cardiovasc Surg 2013;146:1146-52)

The surgical outcomes for hypoplastic left heart syndrome (HLHS) and related variants have progressively improved during the past years, owing to a better understanding of the pathophysiology and improvement in perioperative management. Different surgical strategies have been proposed, including Norwood stage I (NW1), a hybrid procedure, and heart transplantation. NW1 with either a Blalock-Taussig shunt or right ventricle to pulmonary artery

From the Department of Cardiothoracic Surgery, ${ }^{a}$ Great Ormond Street Hospital for Children, London, United Kingdom; and Department of Cardiothoracic Surgery, ${ }^{\text {b }}$ Harley Street Clinic, London, United Kingdom.

Disclosures: Authors have nothing to disclose with regard to commercial support.

Read at the 92nd Annual Meeting of The American Association for Thoracic Surgery, San Francisco, California, April 28-May 2, 2012.

Received for publication May 22, 2012; revisions received Dec 10, 2012; accepted for publication Jan 11, 2013.

Address for reprints: Victor T. Tsang, MD, Department of Cardiothoracic Surgery, Great Ormond Street Hospital for Children, Great Ormond St, London WC1N 3JH, UK (E-mail: Victor.Tsang@gosh.nhs.uk).

$0022-5223 / \$ 36.00$

Copyright @ 2013 Published by Elsevier Inc. on behalf of The American Association for Thoracic Surgery

http://dx.doi.org/10.1016/j.jtcvs.2013.01.051 conduit is currently the procedure of choice in most centers. However, a subset of patients remains whose mortality and morbidity remain elevated because of very poor preoperative conditions. ${ }^{1-3}$

Because of the referral pattern of our practice, we have been treating a number of high-risk patients, often coming from outside the United Kingdom, older than the usual population with HLHS, and frequently with several PCMs. Some of the PCMs were inherent to the patient (chromosomal abnormalities, prematurity, low weight, age), others were directly related to the prolonged high pulmonary recirculation and systemic hypotension, sepsis, and subsequent inadequate end-organ perfusion (renal failure, hepatic failure, necrotizing enterocolitis, prolonged mechanical ventilation, high inotropic requirements).

To lower the operative risk of these patients before the NW1 operation, some centers have adopted a hybrid strategy, with bilateral pulmonary arterial banding (bPAB) and patent ductus arteriosus stenting. However, recent studies have suggested that the hybrid procedure results in poorer physiologic palliation than surgical NW1. ${ }^{4}$ We adopted a 


\section{Abbreviations and Acronyms \\ $\mathrm{bPAB}=$ bilateral pulmonary arterial banding \\ HLHS $=$ hypoplastic left heart syndrome \\ NW1 $=$ Norwood stage I \\ $\mathrm{Q}_{\mathrm{p}} / \mathrm{Q}_{\mathrm{s}}=$ pulmonary/systemic flow ratio}

policy of a rapid 2-stage Norwood procedure for this very unstable patient group. The procedure consisted of bPAB associated with prostaglandin infusion to maintain the patency of the ductus arteriosus to rebalance the pulmonary/systemic flow ratio $\left(\mathrm{Q}_{\mathrm{p}} / \mathrm{Q}_{\mathrm{s}}\right)$ and improve end-organ perfusion. Once the patient had improved clinically, with normalization of hepatic and renal function, we performed early NW1. This strategy, which differs from the hybrid approach, offers an alternative approach for severely ill patients, with no important pulmonary arterial complications associated with bPAB, no significant pericardial adhesions, undisturbed integrity of the aortic arch with antegrade cerebral perfusion, and potentially better cerebral and systemic oxygen delivery. ${ }^{5}$

We have reported our experience with the rapid 2-stage Norwood strategy for these high-risk patients and compared the outcomes with those of low-risk patients undergoing NW1 during the same period.

\section{METHODS}

\section{Patient Inclusion Criteria}

From January 2006 to October 2011, 147 patients presented with HLHS. Of these patients, 17 patients with high-risk HLHS or variant underwent the rapid 2-stage Norwood strategy. These high-risk patients were defined as having $\geq 4$ of the following PCMs: age $>2$ weeks, weight $<2.5 \mathrm{~kg}$, prolonged mechanical ventilation ( $>2$ weeks), systemic sepsis, necrotizing enterocolitis, heart, renal or hepatic failure, coagulopathy, pulmonary edema, sustained hypotension, significant inotropic requirements (adrenaline and/or noradrenaline $>0.1 \mu \mathrm{g} / \mathrm{kg} / \mathrm{min}$ and/or dopamine $>10.0 \mu \mathrm{g} / \mathrm{kg} / \mathrm{min}$ ), generalized edema (anasarca), and previous cardiac arrest. During the same period, 130 patients with standard-risk HLHS with $<3$ PCMs underwent the primary NW1 procedure.

The clinical perioperative and outcomes data were obtained from the patients' medical records. The patient characteristics, including the diagnoses and risk factors, are listed in Tables 1 and 2. The study was registered as an audit/quality improvement project at Great Ormond Street Hospital, and, as such, the need for full ethical approval was waived.

\section{bPAB Procedure}

The $\mathrm{BPAB}$ procedure was performed through a median sternotomy and partial pericardiotomy. With minimal dissection, bPAB was performed sequentially using Silastic slings around the arteries. The size of the $\mathrm{PAB}$ was calibrated using a right-angled Dennis-Brown dissector (external diameter of approximately $4.0 \mathrm{~mm}$ ) and secured with ligaclips (Figure 1). The degree of constriction was considered adequate with an arterial oxygen saturation of $75 \%$ to $85 \%$ using pulse oximetry, and this was usually associated with the elevation of the systemic arterial systolic and diastolic blood pressure. The patency of both pulmonary arteries was checked postoperatively by serial transthoracic echocardiograms. The patency of the ductus arteriosus was maintained by continuous intravenous infusion of prostaglandin $\mathrm{E}_{1}$. After bPAB, all patients stayed in the cardiac intensive care unit and remained mechanically ventilated, with supportive management of the PCMs. Interval NW1 was undertaken when the only remaining PCMs were older age, low weight, and previous cardiac arrest.

\section{NW1 Operation}

The surgical procedure consisted of a NW1 with division of the ductus arteriosus, division of the main pulmonary artery and side-to-side anastomosis with the ascending aorta, aortic arch augmentation, and reconstruction using a pulmonary homograft and atrial septectomy. Pulmonary blood flow was established with a $3.0-$ or $3.5-\mathrm{mm}$, right, modified Blalock-Taussig shunt or right ventricle to pulmonary artery conduit ( $10 \%$ of the patients), according to surgeon preference. Deep hypothermic circulatory arrest at $18^{\circ} \mathrm{C}$ was used for arch reconstruction.

\section{Follow-up}

The outcomes were obtained from most recent medical visits and from direct correspondence with the referring cardiologist. The follow-up data were complete. The mean follow-up period was $2.66 \pm 1.4$ years for the bPAB group and $2.9 \pm 1.6$ years for the low-risk category.

\section{Statistical Analysis}

The data from 147 patients were retrospectively reviewed. The early mortality (30 days) and 1-year actuarial survival of the patients who had undergone NW1 were compared in the 2 groups. Log-rank analysis was used to compare the actuarial survival of the bPAB and low-risk groups, and the results are illustrated as Kaplan-Meier survival curves (Figure 2).

\section{RESULTS \\ Patients}

In the high-risk group were 17 patients ( $76.5 \%$ male), with a weight range of 1.5 to $4.2 \mathrm{~kg}$ (median, 3.0). Their median age at bPAB was 25 days (range, 13-43). The median number of PCMs before bPAB was 7 (range, 5-9). Of the 17 patients, 1 had 4 PCMs and 16 had $\geq 5$ (Table 2 ). In addition, 2 patients were premature, and 2 had chromosomal abnormalities. Three patients had major extracardiac anomalies; one had major hepatic malformation, and the others had craniofacial abnormalities.

The standard risk group included 130 patients $(63.9 \%$ male), with a weight range of 1.9 to $3.8 \mathrm{~kg}$ (median, 3.1). The median age at NW1 was 4 days (range, 1-87). The median number of PCMs before the NW1 was 2 (range, 13). Also, 5 patients were premature, and 5 had chromosomal abnormalities. Genetic abnormalities were detected in the clinical assessment by the pediatric cardiologists, based on wellknown morphologic abnormalities and associated factors.

\section{Rapid Two-Stage Norwood}

In the high-risk group, all 17 patients underwent initial bPAB. The velocity flow across the banded pulmonary arteries was an average of 3.0 to $3.5 \mathrm{~m} / \mathrm{s}$. This was achieved in all patients but 1 , in whom the bPAB had to be tightened 4 days after the original operation. In addition, after bPAB, 3 patients underwent balloon atrial septostomy and 1 patient underwent surgical atrial septectomy because of a restrictive atrial septal defect. 
TABLE 1. Patient characteristics

\begin{tabular}{lccl}
\hline Pt. no. & Gender & Weight at bPAB $(\mathbf{k g})$ & \multicolumn{1}{c}{ Diagnosis } \\
\hline 1 & M & 4.2 & MA, AA \\
2 & M & 2.4 & MA, AA, IAA \\
3 & M & 2.7 & MS, AS, HAA \\
4 & F & 3 & MA, AA \\
5 & F & 3 & MA, AA \\
6 & M & 3 & MA, AA, no RSVC, TAPVC through LSVC on CS \\
7 & M & 3.7 & MA, DORV, IAA \\
8 & M & 3 & LAIso, DORV, AA, common AVV \\
9 & M & 2.7 & DORV, HAA, MA \\
10 & M & 2.45 & MA, HAA, CoAo \\
11 & M & 3.4 & MA, AA \\
12 & F & 3.3 & MA, AA, HAA (severe), TV regurgitation (severe) \\
13 & M & 3.8 & MA, AA, HAA \\
14 & M & 1.5 & MA, AA, HAA \\
15 & M & 3 & MA, AA \\
16 & F & 3.4 & MA, AA, CoAo \\
17 & M & 2.4 & 25, \\
\hline
\end{tabular}

Pt. no., Patient number; $b P A B$, bilateral pulmonary artery banding; $M$, male; $M A$, mitral atresia; $A A$, aortic atresia; $I A A$, interrupted aortic arch; $M S$, mitral stenosis; $A S$, aortic stenosis; $H A A$, hypoplastic aortic arch; $F$, female; $R S V C$, right superior vena cava; TAPVC, total anomalous pulmonary venous connection; $L S V C$, left superior vena cava; $C S$, coronary sinus; DORV, double outlet right ventricle; LAIso, left atrial isomerism; CoAo, coarctation of the aorta; TV, tricuspid valve; $A V V$, atrioventricular valve.

Five patients (29.4\%) died after bPAB, without undergoing NW1. In these patients, the median number of PCMs before $\mathrm{BPAB}$ was 7 and had remained unchanged or had increased after bPAB (Table 2). Of these 5 patients, 3 died of severe sepsis and multiorgan failure, 1 died of a noncardiac pathologic entity (complex congenital hepatic malformation), 1 patient, with restrictive atrial septal defect, died soon after balloon atrial septostomy, of no identifiable cause.

Of the 17 patients, $12(70.6 \%)$ showed improvement after $\mathrm{BPAB}$ and underwent a NW1 procedure. The median number of PCMs before bPAB was 6 . The interval between

TABLE 2. Number of preoperative comorbidities before and after bPAB

\begin{tabular}{lccl}
\hline Pt. no. & $\begin{array}{c}\text { PCMs before } \\
\text { bPAB (n) }\end{array}$ & $\begin{array}{c}\text { PCMs after } \\
\text { bPAB (n) }\end{array}$ & \multicolumn{1}{c}{ Outcome } \\
\hline 1 & 7 & 10 & Died before NW1 \\
2 & 4 & 2 & Alive, TCPC completed \\
3 & 5 & 6 & Died before NW1 \\
4 & 6 & 2 & Died after NW1 \\
5 & 9 & 9 & Died before NW1 \\
6 & 6 & 2 & Alive, Glenn completed \\
7 & 5 & 2 & Alive, Glenn completed \\
8 & 8 & 2 & Died after Glenn \\
9 & 4 & 2 & Died after NW1 \\
10 & 5 & 2 & Alive, Glenn completed \\
11 & 6 & 6 & Died before NW1 \\
12 & 6 & 3 & Died after NW1 \\
13 & 8 & 8 & Died before NW1 \\
14 & 9 & 3 & Alive, awaiting Glenn \\
15 & 9 & 3 & Alive, awaiting Glenn \\
16 & 5 & 2 & Alive, TCPC completed \\
17 & 6 & 2 & Alive, TCPC completed \\
\hline
\end{tabular}

$b P A B$, Bilateral pulmonary artery banding; Pt. no., patient number; $P C M s$, preoperative comorbidities; $N W 1$, Norwood stage I; $T C P C$, total cavopulmonary connection.
bPAB and NW1 depended on the time needed for clinical improvement, when the remaining PCMs were older age, low weight, and previous cardiac arrest. The median interval in this cohort was 8 days (range, 3-68).

The median age at NW1 was 38 days (range, 18-96). One early death $(8.3 \%)$ occurred, in a patient with a dysplastic tricuspid valve and severe regurgitation. Three patients died between 30 days and 1 year after NW1 $(25 \%)$. Two of them died before the stage 2 operation (one of bronchial aspiration and another of acute cardiovascular collapse). The third patient died of a ruptured basilar artery aneurysm 1 month after the bidirectional Glenn operation.

Of the 8 surviving patients, 2 were awaiting stage 2 operations, 3 had undergone a bidirectional Glenn operation, and 3 had had completion of the total cavopulmonary connection at the end of the present study. The 1-year actuarial survival for these patients was $66.7 \%$.

In the standard risk group who underwent primary NW1, the early mortality was $10 \%$ and the 1 -year actuarial survival was $80 \%$. After the NW1 operation, no statistically significant difference $(P=.277)$ was found in early mortality and 1-year survival between those who had undergone initial bPAB and primary NW1 (Figure 2). However, the overall mortality in the high-risk group who underwent initial bPAB was $52.9 \%$ at 1 year.

\section{DISCUSSION}

Since the original description of NW1 in $1983,{ }^{6}$ some modifications have been proposed regarding the type of shunt to use or aortic arch reconstruction to perform; however, the principles of NW1 remain the same. Surgery is normally undertaken in the first week of life, and the results of the NW1 have improved over the years because 


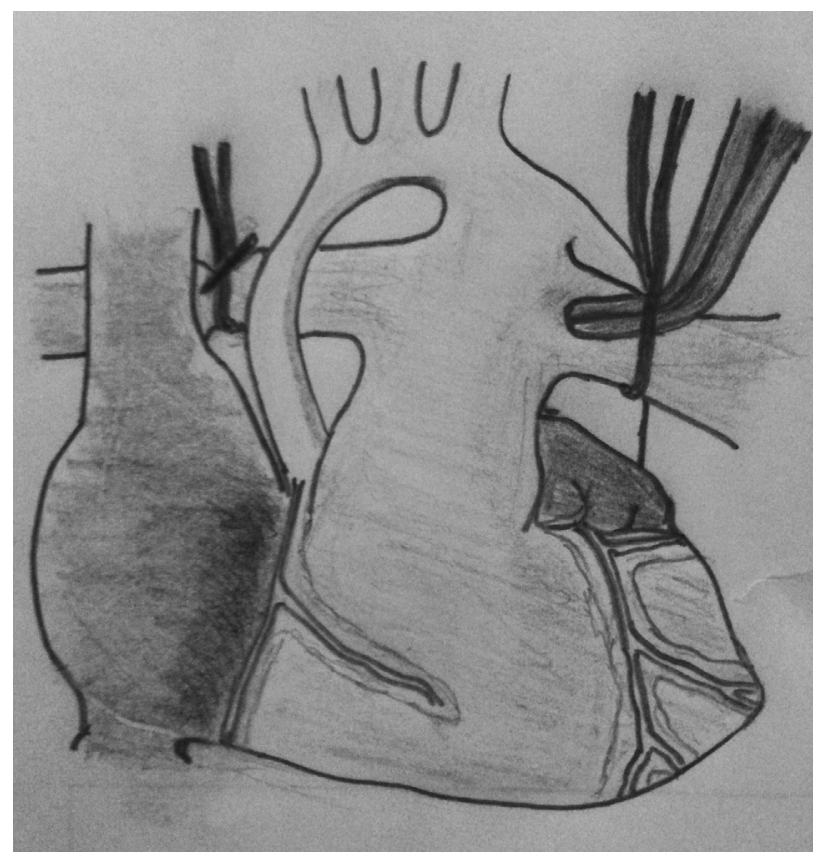

FIGURE 1. Bilateral pulmonary artery banding technique.

of refinement in the surgical and perfusion techniques and a better understanding of the perioperative physiology. Nonmodifiable risk factors have been identified, such as age, weight, chromosomal abnormalities, and a small aorta. However, the mortality and morbidity in high-risk patients with circulatory shock has remained markedly elevated, and alternative therapeutic strategies have been suggested.

Lang and Norwood ${ }^{7}$ reported pulmonary artery banding to limit the pulmonary artery blood flow as a part of the

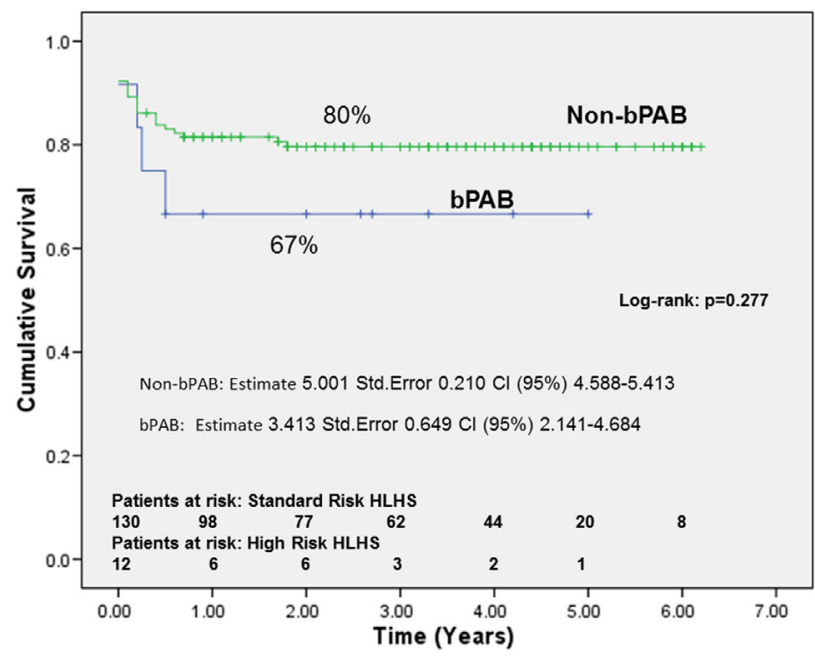

FIGURE 2. Kaplan-Meier curve of actuarial survival after Norwood stage I operation for patients in the standard risk group (no bilateral pulmonary artery banding [non- $b P A B]$ ]) and patients in the high-risk group treated with bPAB before Norwood stage I. Std.Error, Standard error; CI, confidence interval; HLHS, hypoplastic left heart syndrome. palliation. In 1993, Gibbs and colleagues ${ }^{8}$ described the hybrid procedure, and, progressively, several centers have been using it as an alternative or procedure of choice for the treatment of HLHS, especially in high-risk patients. ${ }^{9-12}$ This treatment consists of bilaterally banding the pulmonary arteries and maintaining the patency of the ductus arteriosus using a metal stent. In these patients, the subsequent procedure consists of reconstruction of the aortic arch associated with a bidirectional Glenn operation, commonly known as comprehensive stage II, at 3 to 6 months of age.

Because of the referral pattern of our practice in treating a high proportion of late referrals, we have been treating patients in poor condition, including multiorgan dysfunction and sepsis. We report our experience using the alternative strategy of the 2-stage Norwood procedure in that group of patients. First reported in 2003, ${ }^{13,14}$ this strategy consisted of performing $\mathrm{bPAB}$ and maintaining the patency of the ductus arteriosus with prostaglandin $\mathrm{E}_{1}$, followed by a NW1 operation when the patient was in a more stable condition. The term "rapid 2-stage Norwood" was previously used in a case report by Schmitz and Breuer ${ }^{15}$ in 2008 to describe this approach.

The basic difference between the rapid 2-stage Norwood I and the hybrid procedure is that the latter is followed by the comprehensive stage II operation and aortic arch reconstruction, and the rapid 2-stage is used as a bridge to improve the clinical status and perform the classic NW1. ${ }^{16-19}$ Because the interval between bPAB and NW1 was short, the patency of the ductus arteriosus was maintained pharmacologically, avoiding the inflammatory and vascular injuries caused by the stent hardware. ${ }^{20}$ This strategy offers an alternative approach for severely ill patients, with no important issues related to pulmonary arterial stenosis, no significant pericardial adhesions resulting, and undisturbed integrity of the aortic arch.

Different techniques of bPAB have been reported..$^{21,22}$ In 2010, Kitahori and colleagues ${ }^{23}$ described a scientific approach to guide the degree of branch PA constriction, using a 2-mm-wide Gore-Tex strip (W. L. Gore, Flagstaff, Ariz). The bPAB size was determined from the body weight plus $1 \mathrm{~mm}$ for the left and $1.5 \mathrm{~mm}$ for the right pulmonary artery to achieve an arterial oxygen saturation in the 70s and echocardiographic velocities of 3.0 to $3.3 \mathrm{~m} / \mathrm{s}$.

In practice, however, these very sick and edematous patients exhibit multiorgan dysfunction and often have labile systemic and pulmonary vascular resistance that can change in the postoperative period, after the mechanical adjustment of the $\mathrm{Q}_{\mathrm{p}} / \mathrm{Q}_{\mathrm{s}}$. Furthermore, the pulmonary arteries must be banded sequentially, making it more difficult to optimize the blood flow to each lung at the surgery. Therefore, the physiologic measurements (systemic blood pressure, arterial oxygen saturation, end-tidal carbon dioxide) that are done intraoperatively might not 
be representative of the postoperative behavior of the systemic and pulmonary resistance. Therefore, one must be prepared to readjust the tightness of the bands. Thus, the advantage of using Silastic slings and their anchorage with ligaclips is the ease of adjusting them subsequently to regulate the flow.

In the present series, all the patients who survived bPAB had a significant reduction in the number of PCMs. The adjustment of the $\mathrm{Q}_{\mathrm{p}} / \mathrm{Q}_{\mathrm{s}}$ improves end-organ perfusion, as reflected by the normalization of blood gases and metabolic status. Increasing systemic blood flow could wean the patients from inotropes, improve renal and hepatic function and bowel and peripheral perfusion, thereby reducing acidosis, capillary leak, and anasarca. Despite the overall benefits from the improvement of the $\mathrm{Q}_{\mathrm{p}} / \mathrm{Q}_{\mathrm{s}}$, the direct positive effect on systemic sepsis or primary end-organ failure, such as liver and/or biliary dysfunction, can be limited.

The elevated number of risk factors would possibly contraindicate those patients for a NW1 procedure, and the expected mortality for this group of very sick patients would be very high. Nevertheless, we have demonstrated that $71 \%$ of those patients who underwent the rapid 2-stage Norwood I strategy could then undergo the NW1 and, from then on, achieve outcomes comparable to those of the low-risk HLHS group. However, a subset of patients remains who are so sick they fail to improve after bPAB. An alternative strategy such as extracorporeal membrane oxygenation might need to be considered for these patients, or they might be deemed unsalvageable.

This was a retrospective study, with all the limitations of such a design. The decision to initiate bPAB with an aim of undertaking a rapid 2-stage NWI was determined by the clinical assessment of the patients in the presence of low cardiac output, persistent acidosis, difficulty balancing the $\mathrm{Q}_{\mathrm{p}} / \mathrm{Q}_{\mathrm{s}}$, severe hypoxemia, and cardiac arrest. We did not use any specific algorithm or pathway to dictate when bPAB should be used. Our aim was to demonstrate how the result of NW1 in high-risk patients would compare with that of standard-risk patients, when starting from a similar baseline achieved using bPAB. We did not mean to exaggerate the benefits of bPAB. The idea was to offer an alternative strategy to such severely ill patients and show that if they can undergo the Norwood, they can have comparable survival rates. We recognize that it is important to identify the patients who might have greater benefit from this pathway; however, at this point, rather than increasing the sample size, we have focused on facilitating earlier referrals and transfer to the Norwood center.

\section{CONCLUSIONS}

The purpose of the present study was to assess the effectiveness of a strategy to improve the clinical status of high-risk HLHS patients such that the NW1 operation can be performed with the patient in better condition. It is possible to reduce the number of PCMs by mechanically optimizing the $\mathrm{Q}_{\mathrm{p}} / \mathrm{Q}_{\mathrm{s}}$, in addition to aggressive medical support and resuscitation. The expected mortality for this high-risk group of patients undergoing primary NW1 would be extremely high. Among the patients who survived bPAB to undergo interval NW1, the 1-year survival was not statistically worse than that of the standard-risk HLHS patients.

\section{References}

1. Stasik CN, Gelehrter S, Goldberg CS, Bove EL, Devaney EJ, Ohye RG. Current outcomes and risk factors for the Norwood procedure. $J$ Thorac Cardiovasc Surg. 2006;131:412-7. Erratum in: J Thorac Cardiovasc Surg. 2007; 133:602.

2. Alsoufi B, Manlhiot C, Al-Ahmadi M, Al-Halees Z, McCrindle BW, Mousa AY, et al. Older children at the time of the Norwood operation have ongoing mortality vulnerability that continues after cavopulmonary connection. J Thorac Cardiovasc Surg. 2011;142:142-7.e2.

3. Artrip JH, Campbell DN, Ivy DD, Almodovar MC, Chan KC, Mitchell MB, et al. Birth weight and complexity are significant factors for the management of hypoplastic left heart syndrome. Ann Thorac Surg. 2006;82:1252-7; discussion 1258-9.

4. Hsia TY, Cosentino D, Corsini C, Pennati G, Dubini G, Migliavacca F; Modeling of Congenital Hearts Alliance (MOCHA) Investigators. Use of mathematical modelling to compare and predict hemodynamic effects between hybrid and surgical Norwood palliations for hypoplastic left heart syndrome. Circulation. 2011;124(11 Suppl):S204-10.

5. Li J, Zhang G, Benson L, Holtby H, Cai S, Humpl T, et al. Comparison of the profiles of postoperative systemic hemodynamics and oxygen transport in neonates after the hybrid or the Norwood procedure: a pilot study. Circulation. 2007;116(11 Suppl):I179-87.

6. Norwood WI, Lang P, Hansen DD. Physiologic repair of aortic atresiahypoplastic left heart syndrome. N Engl J Med. 1983;308:23-6.

7. Lang P, Norwood WI. Hemodynamic assessment after palliative surgery for hypoplastic left heart syndrome. Circulation. 1983;68:104-8.

8. Gibbs JL, Wren C, Watterson KG, Hunter S, Hamilton JR. Stenting of the arterial duct combined with banding of the pulmonary arteries and atrial septectomy or septostomy: a new approach to palliation for the hypoplastic left heart syndrome. Br Heart J. 1993;69:551-5.

9. Akintuerk H, Michel-Behnke I, Valeske K, Mueller M, Thul J, Bauer J, et al. Stenting of the arterial duct and banding of the pulmonary arteries: basis for combined Norwood stage I and II repair in hypoplastic left heart. Circulation. 2002;105:1099-103.

10. Bacha EA, Daves S, Hardin J, Abdulla RI, Anderson J, Kahana M, et al. Singleventricle palliation for high-risk neonates: the emergence of an alternative hybrid stage I strategy. J Thorac Cardiovasc Surg. 2006;131:163-71.e2.

11. Akintürk H, Michel-Behnke I, Valeske K, Mueller M, Thul J, Bauer J, et al. Hybrid transcatheter-surgical palliation: basis for univentricular or biventricular repair: the Giessen experience. Pediatr Cardiol. 2007;28:79-87.

12. Caldarone CA, Benson L, Holtby H, Li J, Redington AN, Van Arsdell GS. Initial experience with hybrid palliation for neonates with single-ventricle physiology. Ann Thorac Surg. 2007;84:1294-300.

13. Ishizaka T, Ohye RG, Suzuki T, Devaney EJ, Bove EL. Bilateral pulmonary artery banding for resuscitation in hypoplastic left heart syndrome. Ann Thorac Surg. 2003;75:277-9.

14. Pizarro C, Norwood WI. Pulmonary artery banding before Norwood procedure. Ann Thorac Surg. 2003;75:1008-10.

15. Schmitz C, Schirrmeister J, Herberg U, Kozlik-Feldmann R, Stüber F, Welz A, et al. "Rapid two-stage" Norwood operation in a child with multiorgan failure. Pediatr Cardiol. 2009;30:77-9.

16. Takabayashi S, Shimpo H, Kajimoto M, Yokoyama K, Kado H, Mitani Y. Stage I bilateral pulmonary artery banding maintains systemic flow by prostaglandin $\mathrm{E}_{1}$ infusion or a main pulmonary artery to the descending aorta shunt for hypoplastic left heart syndrome. Interact Cardiovasc Thorac Surg. 2005;4:352-5.

17. Sasaki T, Takahashi Y, Ando M, Wada N, Kawase Y, Seki H. Bilateral pulmonary artery banding for hypoplastic left heart syndrome and related anomalies. Gen Thorac Cardiovasc Surg. 2008;56:158-62. 
18. Sakurai T, Kado H, Nakano T, Hinokiyama K, Shiose A, Kajimoto M, et al. Early results of bilateral pulmonary artery banding for hypoplastic left heart syndrome. Eur J Cardiothorac Surg. 2009;36:973-9.

19. Tomoyasu T, Miyaji K, Miyamoto T, Inoue N. The bilateral pulmonary artery banding for hypoplastic left heart syndrome with a diminutive ascending aorta. Interact Cardiovasc Thorac Surg. 2009;8:479-81.

20. Mitani Y, Takabayashi S, Sawada H, Ohashi H, Hayakawa H, Ikeyama Y, et al. Fate of the "opened" arterial duct: lessons learned from bilateral pulmonary artery banding for hypoplastic left heart syndrome under the continuous infusion of prostaglandin $\mathrm{E}_{1}$. J Thorac Cardiovasc Surg. 2007;133:1653-4.

21. Assad RS, Zamith MM, Silva MF, Thomaz PG, Miana LA, Guerra VC, et al. A novel adjustable pulmonary artery banding system for hypoplastic left heart syndrome. Ann Thorac Surg. 2007;84:2081-4.

22. Bockeria L, Alekyan B, Berishvili D, Pursanov M, Krupianko SM, Zarginava G, et al. A modified hybrid stage I procedure for treatment of hypoplastic left heart syndrome: an original surgical approach. Interact Cardiovasc Thorac Surg. 2010; 11:142-5.

23. Kitahori K, Murakami A, Takaoka T, Takamoto S, Ono M. Precise evaluation of bilateral pulmonary artery banding for initial palliation in high-risk hypoplastic left heart syndrome. J Thorac Cardiovasc Surg. 2010;140:1084-91.

\section{Discussion}

Dr Christopher A. Caldarone (Toronto, Ontario, Canada). Any innovation typically goes through 3 phases: a boom phase, a bit of a disillusionment phase, and then back to a niche phase. The hybrid procedure is no exception.

In the boom phase, it seems like the greatest innovation in the world and widely applicable. Then, a disillusionment phase occurs as the limitations of the innovation became apparent. Finally, it generally finds its place in the niche phase.

At the Hospital for Sick Children, we right now have 4 indications for using the hybrid procedure: (1) as an alternative to the Norwood; (2) pretransplant palliation in patients already listed for transplantation; (3) to delay single ventricle, 2-ventricle decision-making; and (4) as the "salvage procedure" in the group of patients unfit for a Norwood procedure. That is the group you have tackled, and you have tackled it well.

In our version of the salvage procedure, however, we typically will control the patient's pulmonary blood flow with the bands and place a ductal stent. If the patient survives, the patient will subsequently undergo a comprehensive stage 2 procedure. In your paradigm, you have interposed a Norwood procedure between attaining stability and your second stage procedure.

So I guess the most obvious question is: if you have achieved a period of stability, you have succeeded in neutralizing these preoperative comorbidities. Why not just stent the duct and allow the patient to return for a comprehensive stage 2 rather than interposing a new hazard phase associated with a Norwood procedure, which would necessarily include all the potential hemodynamic instability that accompanies having a balanced circulation after a large operation?

Dr Gomide. Thank you for your comments. We think that the hybrid procedure, as mentioned, and has been shown by some of your studies, might not offer appropriate oxygen delivery and that the Norwood procedure would offer better physiologic conditions for patients in terms of antegrade flow and oxygen delivery.

We also fear that a metal stent might provoke coarctation at the point of the ductus arteriosus and interfere in the backflow to the aorta. Thus, we decided to avoid the stent. This is the basic item we wanted to avoid. Also, because the patient was in a better condition, we wanted to offer the NW1 procedure because of these factors. Finally, because we have had satisfactory results with the NW1, we thought that patients in better condition would have a better prognosis with the NW1 than they would have with a stent.

Dr Caldarone. Well, fair enough. I think the hemodynamic studies you refer to really showed that alteration of hemodynamics is mostly due to afterloading, acutely afterloading the neonatal ventricle. Once you are beyond a few days, you have probably passed that hazard phase. Anyway, it is worth ongoing discussion about which strategy might be superior.

The other point I noticed in your report was that the preoperative morbidities were grouped together, and you basically counted them in a scoring system to identify the patients appropriate for the salvage-type procedure. I like that method, but it does suggest that each 1 of these preoperative comorbidities would have an equivalent effect. I was wondering if, in your analysis, did you try to analyze which of the preoperative comorbidities were most important in terms of predicting a poor outcome?

Dr Gomide. No. This is one point we wanted to address. Actually, we could have used a comprehensive score, but this study is not about scoring the patients. We just wanted to keep it simple and to address the number of comorbidities that are easily checked in each patient and show that the patient at high risk can be moved to a lower risk. We did not address the importance of each different risk in terms of the importance for the outcome. Actually, we just wanted to keep it simple and to send the following message: if we have a patient with a high risk, and we reduce this patient's risk, the patient can have the same outcome as a patient with a conventional risk for the Norwood.

Dr Caldarone. Going forward, will you use some more clearly defined paradigm? In other words, if a patient shows up and starts to accumulate preoperative comorbidities and if they hit number 4 , will you then go to the salvage strategy or will you refine that trigger for going to the salvage strategy in the future?

Dr Gomide. No, this is a retrospective study. Actually, we observed that those patients had this high number of comorbidities. Usually in our practice, what happens is that the patient arrives and is assessed clinically. If the patient is in a condition to undergo the Norwood procedure, the patient will receive the Norwood. As we mentioned, the indication for the Norwood depends on the clinical status of the patient, not by counting the number of risk factors. Actually, it is a clinical assessment. Once the patient is stable enough, the patient will undergo the Norwood. It is not a matter of how many preoperative comorbidities are present. This was checked retrospectively, and it was just a cutpoint that was set.

Dr Caldarone. I guess what I am asking is: Will the results of this study guide your decision-making in the future?

Dr Gomide. Well, they certainly will, but not in these terms. I think that the most important message of this study is that those patients with high risk, independently of the number of risk factors, can have the risk category lowered by offering bPAB, and this is the main message. It is not necessary to count the number of risk factors and then decide whether we are going to perform a Norwood or bPAB.

Dr Christian Pizarro (Wilmington, Del). That was an interesting study and a very timely communication, particularly 
based on the discussion we had on Sunday. It seems we are finally reaching a point where we could learn and distill who are the best patients to undergo the hybrid procedure and who are the ones to undergo the Norwood.

Almost about 10 years ago by now, our group and the group in Michigan communicated the effectiveness of pulmonary artery banding to do exactly what you describe. Also, I think that because we embraced that approach more broadly, we went on to treat patients with nonmodifiable factors such as chromosomal anomalies. Not surprisingly, when we communicated those results, 5 years ago at the meeting of the European Association for Cardio-Thoracic Surgery, the outcome, when you looked beyond the second stage, was no different, and it was close to $50 \%$ to $60 \%$ mortality.

I think that although you have shown that there was no difference at 1 year, you do not have the power to make that statement. Also, I think it is likely there will be a difference. So, you have $80 \%$ survival compared with about $62 \%$. Experience has told us that, for example, there are certain conditions that you might think you would be able to modify, such as renal dysfunction. For instance, a patient presents in shock with significant renal dysfunction, liver dysfunction, and whatnot, sometimes you are able to help that patient recover normal function, not just to make urine and lower their creatinine but to completely resolve their dysfunction. However, some of those patients will not.

So, some of the difference that you observe in the high-risk group is probably related to, for example, ventilator-associated lung disease, residual renal dysfunction, and so forth. Did you have an opportunity to actually study that patient population, the ones who were in the high-risk group and had lower survival at 1 year to determine how many of those factors that were perceived as recoverable actually had a sequela and how that affected the mortality?

Dr Gomide. Yes. We have had 5 deaths in the bPAB group. Three patients died of sepsis and severe multiorgan failure, one of a complex congenital hepatic malformation, and one died after a Rashkind procedure, unexplainably. Thus, the 3 patients who died of sepsis and the patient who died of congenital hepatic dysfunction are patients that perhaps we could not offer improvement by banding the pulmonary arteries, because the adjustment of the Qp/Qs might improve the end-organ perfusion but might not offer an improvement to the inflammatory response caused by sepsis. Thus, perhaps the septic patient will not have the same improvement as the nonseptic patient, or, even some septic patients who respond more aggressively to the infection might not respond to the bPAB, while some others would respond. To identify those patients, we will additional studies.

In the case of the primary end-organ failure, perhaps we do not improve it because it is the primary failure of the organ, and improving the perfusion might not correlate with better outcomes.

Dr Pizarro. As you accumulate more experience, I would encourage you to actually study and determine how many of those patients with a recoverable lesion actually had a sequela and what the role of that was later in their life.

Dr Shunji Sano (Okayama, Japan). We have also adopted the rapid 2-stage banding for high-risk patients, as we presented previously. In our series, the rapid 2-stage operation occupies almost $20 \%$ to $30 \%$ of our series. Our indication for the rapid 2-stage is slightly different from yours. Most of our indications have been the patient with HLHS and an intact atrial septum or restrictive atrial septal defect with high pulmonary vascular resistance. I am sure you have similar patients in your series, but your indication was different. What is your strategy for the patient with an intact atrial septum or restrictive atrial septal defect or associated with total anomalous pulmonary venous drainage. Do you do a rapid 2-stage in these patients or just the ordinary Norwood?

Dr Gomide. Well, these patients with the restrictive atrial septal defect usually undergo the Norwood. Our strategy differs from yours in that we are not analyzing the usual anatomically related risk factors but the modifiable risk factors. Therefore, the patients had the same anatomic risk factors as the usual patients. We actually excluded the patients with restrictive atrial septal defect from this study. However, all the other commonly known risk factors, such as aortic atresia or total anomalous pulmonary venous drainage, were not considered risk factors in our group, because our results did not show different outcomes for these patients. Thus, they were treated in terms of the clinical risk factors that were related. 